\title{
IRLANDA: LA ESTRATEGIA DE LA NEUTRALIDAD «SINGULAR» Y LOS ELEMENTOS APLICABLES PARA COLOMBIA
}

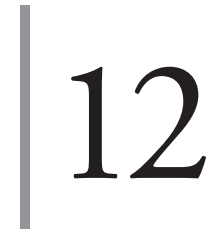

\author{
Andrés Felipe Cardona Orozco \\ Sandra Milena Celeita Roa \\ Mónica Johanna Pisciotti Ramírez
}

\section{Introducción}

Desde la caída del muro de Berlín y la disolución de la Unión de Repúblicas Socialistas Soviéticas (URSS) a finales del siglo XX, el mundo contemporáneo se ha movido entre la globalización, los conflictos internos, las crisis internas, la apertura de mercados y la gran preponderancia de los Estados Unidos en el escenario internacional. Si bien es cierto que la década de los 90 trajo consigo una serie factores y escenarios complejos, el inicio del Siglo XXI presentó nuevos factores que han hecho que el mundo esté atravesado por diversidad de actores, situaciones, amenazas y crisis regionales. Algunos ejemplos de esto son las problemáticas de Siria, África y la Península de Corea. La incorporación del terrorismo en la agenda internacional, después de los atentados del 11 de septiembre en los Estados Unidos). Esta pluralidad de elementos cumple un papel fundamental en la evaluación que realizan los Estados para buscar mantener su estabilidad y supervivencia, y por consiguiente la de sus ciudadanos.

Factores como el terrorismo, el cambio climático, el crimen transnacional y temas como los acuerdos económicos y comerciales, son piezas claves para comprender gran parte de la dinámica internacional y la actuación de los Estados. Una realidad indiscutible en la actualidad es que las naciones no pueden actuar de manera independiente o en solitario, por lo cual recurren a acciones conjuntas, bilaterales o multilaterales, para buscar su supervivencia (Álvarez Calderón \& Rodríguez Beltrán, 2018). 
Una de las respuestas establecidas frente a estos temas y amenazas radica en la construcción del Libro Blanco de Defensa ${ }^{1}$. Este documento se desarrolló por los gobiernos para presentar de manera pública su análisis, medidas y lineamientos estratégicos para contrarrestar o mitigar una posible amenaza o riesgo que atente contra territorio, la soberanía o la población de las naciones.

El presente capítulo tomará el caso de la República de Irlanda cuyo su libro, White Paper, contempla la política de defensa para los próximos diez años y provisiona al Gobierno de un marco referencial por medio del cual busca una respuesta flexible y adaptativa a los cambios en el entorno de la seguridad y la defensa (Department of Defense, 2015).

Charles Phillipe-David afirma que la seguridad puede ser entendida como una situación en donde un sujeto considera que no está amenazado por ningún peligro o que está en la capacidad de hacerle frente sí se hace realidad (David, 2008, pág. 65). Por otra parte, también se definirá la seguridad como «la ausencia de amenazas militares y no militares que pueden cuestionar los valores centrales que quiere promover o preservar una persona o una comunidad y que conllevan un riesgo de utilización de la fuerza» (David, 2008). La anterior definición ayuda a comprender la visión irlandesa de seguridad. En este sentido, dentro del Libro Blanco se contempla una visión amplia del término, y se alude tanto a amenazas militares tradicionales, como a nuevas amenazas. Entre ellas se destacan el terrorismo, los ciberataques, el cambio climático, y la proliferación de Armas de Destrucción Masiva (ADM), entre otras (Department of Defense, 2015. Págs. 10-20).

Si bien es cierto que al definir el término seguridad y contrastarlo con lo planteado en el Libro Blanco de Defensa, la concepción y visión sobre la seguridad no solo se entiende desde la perspectiva estatal, sino también desde la perspectiva de la Seguridad Colectiva; en especial en relación con la Unión Europea (UE). Al ser Irlanda parte de la UE, su definición de seguridad parte en esencia de la comprensión del marco de Seguridad Europeo contemplado en el Tratado de la UE de 1992 (en adelante TUE) y del Acuerdo de Niza de 2001. En estos acuerdos, se contempla que la seguridad es un compromiso de los 25 Estados firmantes (en su

1 Mucho se ha hablado sobre los contenidos y lo que debe reflejar un Libro Blanco de Defensa. Sin embargo, dentro de las muchas revisiones realizadas sobre el tema y, este análisis se hace con base en lo expuesto y discutido en el texto Libros Blancos de Defensa. Concertación politica y diseño estratégico comparado, coordinado por Juan Ramón Quintana. En dicho texto se plantea como conclusión que los Libros Blancos de Defensa responden a temas relacionados con la identidad nacional y valores nacionales que un Estado busca defender. Al mismo tiempo defienden la soberanía y la independencia nacional. En este sentido, se concluye que dicho documento fija la postura oficial en temas como la seguridad internacional y la forma a través de la cual un determinado Estado puede contribuir a la estabilidad y la construcción de paz (Quintana T., 2001, págs. 231-245). 
momento), en donde se busca la defensa de valores comunes, el sostenimiento de la paz, el fortalecimiento de la seguridad en todas sus formas y la consolidación de la democracia y del Estado de derecho, mientras se busca la seguridad internacional (López-Jacoiste Díaz, 2006). Para tales efectos, la UE ha logrado consolidar dos elementos claves: la Política Europea de Seguridad y Defensa y la Política Exterior de Seguridad Común. Estos lineamientos logran consolidar la Estrategia Europea de Seguridad. Pese al gran avance que ello significa en términos de proyección, lo más complejo de estos elementos es la falta de consenso de los Estados miembros para lograr su articulación e implementación.

Luego de definir o establecer el significado de seguridad, es imperativo plasmar aquello que se entiende por defensa. En primera instancia, el término hace referencia a las condiciones y acciones que emprende un Estado para garantizar su seguridad. Esto convierte a la Defensa en un medio (capacidades) por el cual se buscaría lograr la seguridad. El término no implicaría necesaria y exclusivamente las capacidades militares, sino la articulación de diversos sectores en la búsqueda de la seguridad y la supervivencia del Estado.

En contraste, autores como, Charles Phillipe-David (2008) logran definir el concepto de defensa como «Despliegue (a veces intervención) con el fin de prevenir un ataque o minimizar los daños si esto sobreviene. La fuerza es exhibida con la esperanza de que no será usada» (David, 2008). En esta definición se hace énfasis en el uso de las Fuerzas Militares para la búsqueda de la seguridad. Así mismo, la defensa debe entenderse como todas las acciones que desarrolle un Estado para garantizar su seguridad. Dentro de ellas se encuentran: la diplomacia, la economía, el campo social y político, y, desde luego, las Fuerzas Militares. Estas últimas son, dentro del concepto de defensa, el primer actor en caso de una agresión o intento de agresión.

La Defensa de un Estado tiene que ver con una serie de elementos que, bien encaminados, estructurados y ejecutados, lograrán conducir hacia una situación de seguridad deseada. De ahí entonces, se comprende por qué dentro de los Libros Blancos de Defensa no solamente se hable de los temas propiamente militares, sino de una serie de temas relevantes para un país. Esto reafirma la necesidad de una visión ampliada del término seguridad mencionada anteriormente.

Ahora bien, teniendo como punto de partida las definiciones anteriores, el presente capítulo tiene como propósito la revisión del Libro Blanco de Defensa de Irlanda desde una perspectiva analítica basada en una revisión documental. Este estudio académico profundiza en el trasfondo geopolítico, geoestratégico y de lógica estratégica que subyace a la política de neutralidad y sus decisiones en materia de seguridad y defensa. 
De ese modo, este estudio explorará los elementos históricos que son claves en la definición y comprensión del concepto irlandés de neutralidad, sus instituciones, organización y funcionamiento, y sus relaciones con el entorno regional. La comprensión histórica se hace necesaria para explorar las características de la neutralidad de Irlanda y para ello se debe tener en cuenta su integración a la Unión Europea y su colaboración en misiones de paz con la OTAN. Finalmente, se realizará un análisis sobre las estrategias propuestas por este país que pueden llegar a ser un ejemplo para Colombia en su construcción de Libro Blanco.

\section{Información General de la República de Irlanda}

Para entender la postura de Irlanda en el contexto regional e internacional es necesario conocer su ubicación geográfica y algunos elementos históricos y descriptivos sobre su cultura y sobre su estructura política.

Este Estado soberano se encuentra ubicado en la isla de Irlanda al noroeste de Europa y forma parte del archipiélago británico. Sus fronteras están compuestas: al norte con Irlanda del Norte (o Reino Unido) y los divide Lough Foyle, que es como se le conoce a esta división entre los dos Estados; al este, se encuentra el Reino Unido y los divide el mar de Irlanda; al sur limita con el Mar Céltico; y al oeste con el Océano Atlántico (Oficina de información diplomática, 2018).

El sistema de Gobierno irlandés es una República Parlamentaria, la cual cuenta con un presidente, Michael D. Higgins y un primer ministro (Taoiseach), Leo Varadkar. El Parlamento Irlandés o Oireachtas, al ser bicameral cuenta con una Asamblea o Cámara Baja (Dáil Éireann), compuesta por 158 miembros, elegidos de manera representativa por 5 años y el Senado o Cámara Alta (Seanad Éireann), compuesta por 60 Senadores, los cuales están distribuidos de la siguiente manera; 43 son elegidos de forma indirecta por un Colegio Electoral, conformado por miembros de la Asamblea, miembros salientes del Senado, miembros de Concejos municipales y de los condados; 11 son elegidos por el Primer Ministro y los 6 restantes electos por representación universitaria (tres por parte de la Universidad de Dublín o Trinity College y tres por la Universidad Nacional de Irlanda) (Central Intelligence Agency, 2018).

\subsection{Breve Historia de Irlanda}

Irlanda sufrió a lo largo de su historia invasiones de vikingos e ingleses, quienes lograron forjar gran parte de la historia política y social del país hasta el día de hoy. 
Es una historia que pasa por problemas políticos, feudalismo, hambruna y ríos de sangre que aún se conservan en la memoria de los irlandeses.

Con la llegada de los primeros celtas en el año 250 a. C. a la isla, lograron darle un gran impulso al desarrollo del pueblo irlandés (Borges, 2016, Pág. 6). Ellos transmitían su conocimiento a los habitantes de la isla. Esto se derivó en la aparición de relatos, sagas y leyes. Posteriormente, llegaron los gaélicos y ocuparon parte de Irlanda y Escocia, De ellos se adoptó la cultura e idioma (O’Beirne Ranelagh, 2014).

La isla comienza a recibir importancia, por parte de otras naciones, pero sobre todo por parte del Rey Enrique VIII², quien comenzó a preocuparse por llegar a la ella, «introduciendo con ello la Reforma Protestante. Posteriormente, se intentaría llevar a cabo un proceso de colonización en Irlanda por parte de los ingleses, en especial de la mano de Oliver Cromwell, con personas procedentes de Escocia y Gales» (Rodríguez Fernández, Aitor Javier; 2015, Pág. 10).

Tanto ingleses como irlandeses, alimentaron a lo largo del tiempo la desconfianza mutua por medio de una serie de agravios que incluían matanzas, hambrunas, detenciones y distintos tipos de represalias. Esto era constantemente recordado y celebrado por ambas sociedades como un intento por no olvidar los daños cometidos, así como por legitimar las acciones políticas y armadas con el fin de consolidar, cada cierto tiempo, un tipo de dominio territorial (Monroy, 2015, pág. 34).

Lo anterior muestra cómo la historia de Irlanda se caracterizó por invasiones por parte de romanos en el Siglo VII y, posteriormente, por el Reino Unido. Dicha duración y relación se sostuvo hasta el siglo XX más específicamente hasta 1922 luego de la firma del Tratado Anglo-irlandés con el que se logra su independencia (Encyclopedia Britannica, 2018). Así mismo, dentro de la isla existieron divisiones y enfrentamientos religiosos entre católicos, protestantes y cristianos anglicanos.

Las invasiones y luchas evidencian algunos elementos que son centrales en la comprensión moderna y contemporánea de este país, que a su vez dará luces sobre la relación con su vecino natural, el Reino Unido. Para el año 1912, el parlamento de Londres votó en favor de la creación de un Estado irlandés como ciudad autónoma del Imperio Británico. Sin embargo, esta iniciativa no se prosperó debido al inicio de la Primera Guerra Mundial, en 1918.

El Levantamiento de Pascua fue una rebelión que tuvo lugar en abril de 1916 contra la monarquía británica, en donde los independentistas y republicanos irlandeses intentaron tomar el control del país para lograr la independencia. Este hecho

2 Durante su reinado, Enrique VIII, comenzó con el sometimiento conquista de la isla. 
generó la división de la isla irlandesa, creando Irlanda del Norte y la Irlanda del Sur. La primera proclamando su voluntad de seguir bajo el mandato británico; mientras que la segunda, se afirmó como un Estado libre.

Para 1919, el Ejército británico reprimió al Sinn Fein, de tal manera que la guerra de independencia irlandesa llegó a su fin; esto gracias a la votación a favor del Parlamento. Para 1922, el pueblo sale a votar, logrando una independencia de manera democrática. Finalmente, para el año 1949 se cierran los últimos vínculos que los unían como parte del Reino Unido, luego de la proclamación por parte del entonces Fine Gael del Replublic Of Ireland Act (Acta de la República de Irlanda). Este tratado reconoció la independencia y la soberanía de Irlanda, y dio paso a lo que se puede denominar la Segunda República Irlandesa (Encyclopedia Britannica, 2018).

Ahora bien, desde la independencia del país, su actuación internacional se ha enmarcado dentro de una funcionalidad, la cual se enfoca claramente en la cooperación y la búsqueda de la paz. De esta manera, su actuación es coherente con lo establecido en su Constitución Política en el artículo 2933, en el cual se habla de las relaciones internacionales. En él se manifiesta su devoción ideal hacia la paz y la cooperación amistosa entre las naciones, al igual que aboga por la solución pacífica de los conflictos. (Government of Irland, 2015, Pág. 108).

Cabe resaltar que desde 1992 se ha reconocido a Irlanda como un país cooperante en el contexto regional y mundial. Sin embargo, dentro de las cooperaciones reforzadas ${ }^{4}$ establecidas por la UE, Irlanda ha mantenido un papel neutral debido a sus relaciones con el Reino Unido. Lo anterior se evidenció en la realización de operación y ejercicios, como lo fue el caso de la Operación Concordia ${ }^{5}$. En ella, el Estado no aportó personal militar. Por otra parte, en el tratado de la UE en 1991, la República de Irlanda se convirtió en un Estado observador. (Instituto Español de Estudios Estratégicos, 2005).

\subsection{Aproximación al concepto de neutralidad}

$\mathrm{Al}$ realizar la revisión bibliográfica, el concepto de neutralidad en las relaciones internacionales tiene un significado y trasfondo que encuentra sus raíces en

3 En el aparte de relaciones internacionales, en el artículo 29 del aparte 1 y 2 se habla del papel preponderante de Irlanda en la solución pacífica de controversias y la importancia de la cooperación entre las naciones.

4 Según el Artículo 27 del tratado de la Unión Europea, dichas cooperaciones se aplicarán en una acción en común y no podrán referirse en cuestiones que tengan repercusión militar o de la defensa.

5 Acción de la UE realizada el 31 de marzo en la que se da inicio a la operación en Yugoslavia, con el fin de lograr el cumplimiento de los acuerdos firmados y evitar un escalamiento al conflicto de Macedonia. 
una decisión que puede comprenderse con mayor profundidad desde la perspectiva realista o liberal. Sin embargo, antes de abordar dichas perspectivas, es necesario hacer una revisión del término desde su significado simple hasta su concepción jurídica.

Se entiende por neutralidad, según lo planteado por Russell y Tokatlian (2013), y la Real Academia de la Española (RAE), como la «cualidad o actitud de ser neutral». El sujeto neutral «no es ni de uno ni de otro» $\mathrm{y}$ «entre dos partes que contienden, permanece sin inclinarse a ninguna de ellas», en términos de naciones o Estados, más no de personas o cosas. Entonces, ser neutral significa «que no participa en una guerra movida por otros y se acoge al sistema de obligaciones y derechos inherentes a tal actitud».

En la historia del derecho y de las relaciones internacionales, la neutralidad se podría definir como la condición de imparcialidad de un Estado y, por lo tanto, no participación en las hostilidades cuando otros países están en guerra (Serrano Álvarez, 2018). Desde ese punto de vista, la neutralidad es claramente un derecho de los Estados que, además de proteger jurídicamente a la nación que la adopta, favorece la seguridad internacional. En concordancia, la neutralidad limita el alcance de la guerra (al disminuir el número de beligerantes), modera la destructividad de un conflicto armado (al reducirse los territorios y poblaciones afectados por el enfrentamiento) y eleva la posibilidad de terminar un conflicto entre Estados (al proveer una potencial mediación entre las partes). La concepción desde el derecho internacional no solo es necesaria sino central para comprender las condiciones de vigilancia de la neutralidad establecida por un país 6 .

Según Novakovic (2013), la neutralidad, como se conoce actualmente, surge en su primera forma luego de las guerras napoleónicas y del Congreso de Viena de 1815. En este entonces las potencias europeas de la época reconocieron la neutralidad permanente de Suiza y declararon que su independencia e integridad territorial eran del interés común para el continente. A este acontecimiento le siguió el reconocimiento de independencia de Bélgica en 1830 y su neutralidad en 1831.

La neutralidad como fue concebida en La Haya en 1907, se puso a prueba en el marco de las Guerras Mundiales. Mientras en el escenario internacional que contempló el tratado se diseńaban normas para guerras limitadas, se comenzaron a vivir guerras totales que no se limitaban a las partes combatientes. Las Guerras Mundiales contaron con notables desarrollos técnicos y tecnológicos, como la

6 Para efectos de la comprensión jurídica de la neutralidad es necesario tener en cuenta la V Convención de La Haya de 1907 sobre Derechos y Deberes de los Poderes Neutrales en Caso de Guerra Terrestre y la XIII Convención de La Haya relativa a los Derechos y a los Deberes de las Potencias Neutrales en la Guerra Marítima. 
guerra submarina y aérea, en donde no se buscaba la derrota militar del enemigo sino su destrucción total. De esta forma, la neutralidad comienza a evidenciar ciertas dificultades. Un claro ejemplo de esto fueron los cuarenta Estados que se declararon neutrales en la Primera Guerra Mundial, solo seis seguían siéndolo al final (Novak, 1995).

Frente al concepto de neutralidad, Novak (1995) logra identificar por lo menos dos modos:

a. Neutralidad ocasional: Aquella que adopta de manera discrecional un Estado ante un conflicto bélico concreto del que quiere permanecer al margen. Esto le otorga una serie de derechos, pero, sobre todo, dos obligaciones claves:

- Abstención, en el sentido de no prestar ayuda directa o indirecta a ninguno de los beligerantes.

- Imparcialidad, pues implica el deber de tratar por igual a todos los beligerantes.

La neutralidad debe traducirse para el Estado en el respeto de su territorio por los beligerantes y en poder mantener relaciones comerciales con todos los Estados, incluidos los que están en guerra.

b. Neutralidad permanente: Tiene los mismos derechos y obligaciones para los Estados que en el modo de neutralidad ocasional. Sin embargo, su diferencia radica en que un Estado con neutralidad permanente debe ser más riguroso en el cumplimiento de sus obligaciones, sobre todo en cuanto a la imparcialidad, y evitar al máximo alianzas o compromisos que le lleven a perder dicha neutralidad.

Se debe considerar que la neutralidad por sí sola no garantiza la independencia y soberanía de un Estado, como lo prueban las Guerras Mundiales; la voluntad política de las potencias pesa sobre el respeto a los Estados declarados neutrales. De ahí que Suiza haya podido garantizar su estatus de neutralidad. Vale la pena resaltar que Suiza le apuesta a un plan de contingencia a partir de una neutralidad armada. Es decir, capacita a su población e invierte en seguridad y defensa para enfrentar de una potencial agresión.

Por otra parte, desde las relaciones internacionales, la neutralidad tiene un concepto polisémico. Su significado tiene una visión, forma de aplicación y actua- 
ción dentro del sistema internacional que deviene del contexto en el que se dé. Pese a la existencia de diversas escuelas y visiones sobre el tema, las que quizás logran consolidar de mejor manera la visión sobre este tema son las teorías realistas y liberalistas.

En el caso del realismo, la neutralidad se mide de acuerdo con su impacto sobre el poder relativo de un actor. De acuerdo con esta óptica, los realistas concluyen que la neutralidad, tiende a producir consecuencias negativas para los intereses nacionales de los neutrales. La neutralidad se fundamenta en una evaluación del decisor político para garantizar la supervivencia del Estado y de sus intereses, ya sea por la proximidad y amenaza de una potencia, o, por el contrario, que esa cercanía le garantice su seguridad y, por ende, vea útil declarar su estado de neutralidad. Adicionalmente, el concepto de neutralidad establecido desde esta perspectiva implica una postura pragmática que depende de la evaluación de todos los elementos de seguridad disponibles y del balance de poder internacional. Dado lo anterior, se debe considerar que, dentro de dicha neutralidad, el Estado también asume como necesario establecer una posición armada que garantice su propia protección y crear, de esta forma, lo que se conoce como «neutralidad armada» (Neal G., 2006, p. 13-15).

Desde la perspectiva liberal, la neutralidad está ligada a un debate moral. Es decir, si es moralmente aceptable para los Estados declararse neutrales dependiendo de lo justo o injusto de la guerra. Su punto de partida surge del reconocimiento de la soberanía y de la existencia de un ordenamiento legal internacional, por medio del cual se respeta el derecho a la neutralidad. Con esta percepción, la concepción de la seguridad implica que se pueda participar dentro de un escenario de seguridad colectiva, sin que ello conduzca a que el país neutral incremente su poder militar y esté en la capacidad de proteger su propia seguridad (Neal G., 2006). Por consiguiente, el concepto de neutralidad adquiere mayor valor dado el alcance de los Convenios V y XII de La Haya de 1907. Como norma internacional, dan sustento y establecen las normas bajo las cuales se rigen los países neutrales y los elementos para que las partes en conflicto respeten dicha condición.

\subsection{Orígenes y desarrollo de la neutralidad de Irlanda}

La neutralidad irlandesa surgió, en principio, como mecanismo para garantizar la independencia y soberanía de un naciente y frágil Estado. Este proceso ocurrió en un contexto internacional de guerra entre las potencias europeas, que estuvo antecedido por un pasado colonial inglés sobre la isla de Irlanda desde el siglo XII. 
Ahora bien, la búsqueda de la independencia a principios del siglo XX marcaría el camino hacia la búsqueda de una neutralidad dentro del contexto europeo. Muestra de ello es el Tratado Anglo-Irlandés de 1921 el en el cual se divide la Isla entre los territorios británicos y los territorios irlandeses. Sin embargo, al revisar dicho tratado se pude encontrar que el Artículo 7 estableció que algunas bases del sur del Irlanda estuvieran bajo dominio británico (Keatinge, 1984 citado por Neal G., 2006, Pág. 9). Esto facilitó su uso en tiempo de guerra y, a su vez, favoreció la posición de Irlanda dentro una zona de Exclusión Naval y protegida por el Reino Unido.

Desde una óptica constitucional, la neutralidad de Irlanda tiene su sustento en la Constitución de 1937. En su Artículo 29 se dice que el Estado «afirma su devoción por el ideal de la paz y la cooperación amistosa entre las naciones fundadas en la justicia y la moralidad internacional». Además, hace mención de «su adhesión al principio de la solución pacífica de las controversias internacionales» y «el derecho internacional como norma de conducta en las relaciones con otros Estados» (Constitución de Irlanda, 1937).

Desde una visión de la historia independiente Eamonn de Valera logró establecer las bases de la neutralidad y apeló a la neutralidad para garantizar la independencia y la soberanía. En un extenso seguimiento a sus declaraciones y a las de su Ministro de Defensa, Frank Aiken, se evidencia la necesidad de aplicarle una dosis de realismo a su estrategia al apelar a una «neutralidad armada». En palabras de Valera esto se describe como «hay que tener un poco de fuerza» (Novakovic, 2013).

Uno de los elementos centrales para la comprensión de la neutralidad irlandesa, radica en que sus Fuerzas Armadas no han sido históricamente fuertes y grandes en personal (Keatinge, 1984 citado por Neal G., 2006, pág. 17). Además, ante la falta de una industria de defensa y los pocos recursos armamentistas que poseía el país, el Gobierno irlandés trató de obtener armamento de los aliados, encontrándose con la obstrucción de Gran Bretańa y la no cooperación de los Estados Unidos (Novakovic, 2013). A pesar de no consolidar la pretensión de una «neutralidad armada», Irlanda le ha apostado a una estrategia política de neutralidad militar, es decir, ha trabajado en promover la paz y la seguridad internacional y la no pertenencia a alianzas militares.

La neutralidad no militar y su activismo a favor de la paz y la seguridad internacional, llevan a Irlanda a aplicar una «neutralidad activa» lo cual va acorde al sostenimiento de la paz de las Naciones Unidas y el Tratado de No Proliferación. En cuanto a las iniciativas de descolonización, Irlanda se opone al apartheid sudafricano. Por otro lado, acepta en su país refugiados y se opone a la financiación estadounidense de paramilitares de América del Sur (Novakovic, 2013). 
Además de garantizar la soberanía e independencia y mantener la cohesión interna, la neutralidad irlandesa le ha dado prestigio internacional al país. Su estrategia le ha permitido compensar sus debilidades para tener una neutralidad armada y enfocarse en otras áreas como el desarrollo social y económico. De esta manera, Irlanda confía su seguridad a los principios de seguridad colectiva de las Naciones Unidas. Estos factores también ayudan a comprender por qué Irlanda no se ha adherido a la OTAN. Además, explica su ingreso tardío en la entonces Comunidad Económico-europea (CEE), hoy Unión Europea (UE), y su resistencia, excepciones y aclaraciones a las recientes reformas de esa misma organización. Sin embargo, Irlanda comparte valores políticos propios de occidente.

Para el caso de la OTAN sus motivos para no adherirse eran económicos: Irlanda no estaba en condiciones de gastar el dinero requerido por la organización en 1947. Una adhesión requería el doble de los gastos en defensa para cubrir el gasto medio de los miembros de la OTAN, sobre la base de una proporción del Producto Interno Bruto (PIB). Otro elemento para considerar fue la pérdida de la independencia en la política exterior. En el caso de la CEE, De Valera proyectó una Europa Federal, por lo cual no era prudente, como nación, entrar en una federación política que implicaba una alianza militar. En concordancia, Irlanda pasaba por el temor de ser arrastrada a una posible guerra entre las dos superpotencias en el marco de la Guerra Fría.

Otro aspecto para destacar es la decisión constitucional y política de someter a referendo diversas reformas a la Constitución en aspectos que afectaban la seguridad y la defensa irlandesas. Esto obedece a un cálculo económico, más no a la integración a una estructura militar que, en su momento, estaba representada por la OTAN o la Unión Europea Occidental (UEO).

En lo que se refiere a su relación e integración con Europa se destacan los siguientes referendos (Villadangos, 2012):

Adhesión a las Comunidades Europeas en 1972; Acta única europea en 1987; Tratado de la Unión Europea en 1992; ratificación del Tratado de Ámsterdam en 1998; ratificación del Tratado de Niza (2002); ratificación del Tratado de Lisboa (2009); ratificación del Tratado sobre Estabilidad, Coordinación y Gobernanza en la Unión Económica y Monetaria (2012).

Se destaca Villadanga, como un tratado con fuertes implicaciones sociales y económicas, aprobado en 2012 por el electorado, al mismo tiempo que el Tratado de Lisboa y el Tratado de Niza fueron negados. Lo anterior ocurrió teniendo dado que el tratado de 2012 dependía de la ayuda de la UE para superar la crisis econó- 
mica irlandesa, mientras que los de Lisboa y Niza, en consideración de los votantes, implicaban ceder en su soberanía, autonomía en política exterior, de seguridad y de defensa a favor de los países más grandes de Europa.

El escenario pos Guerra Fría, desencadenó múltiples y variadas amenazas más allá del tradicional conflicto interestatal, ya que fueron amenazas que desbordaron y, en algunos casos, desplazaron a los Estados Nacionales. Tal es el caso del terrorismo o de las amenazas en el ciberespacio. De ahí que la neutralidad vendría a ser poco útil para que países como Irlanda puedan garantizar su propia seguridad y defensa.

En el siglo XXI, la neutralidad irlandesa fue erradicada en favor de los compromisos de defensa mutua y la pertenencia a la alianza militar con la UE en el nombre de la «solidaridad». El fracaso de los sucesivos gobiernos para convencer a la opinión pública, junto con su decisión de erradicar la neutralidad en la década de 2000, sin duda, traerá más problemas políticos en el futuro. Esto pone a los gobiernos irlandeses y a la UE en la posición de promocionar la política exterior, de seguridad y defensa común por medio de los valores del Estado de Derecho, la democracia, los derechos humanos y libertades fundamentales.

Por ahora, tanto los gobiernos de Irlanda como la UE han buscado disminuir la resistencia de la población y de los sectores políticos y sociales del país con mecanismos como la "Cláusula de Irlanda». En esta se afirma que las disposiciones «no afectarán al carácter específico de la política de seguridad y defensa de determinados Estados miembros» que tienen un efecto claro en el Artículo 42. En su séptima cláusula, sobre la defensa mutua, se habla de la protección de la neutralidad y estipula que esta obligación de ayuda y asistencia no afectará al carácter específico de la política de seguridad y defensa de determinados Estados miembros, lo cual en la realidad plantea preguntas sobre el alcance exacto de esta obligación. Otro hecho relevante fueron las declaraciones de junio de 2009 del Gobierno irlandés para aclarar el significado del Tratado de Lisboa. En ellas afirmó que el Tratado de Lisboa no afecta la política tradicional de Irlanda de neutralidad militar.

Sin embargo, la referencia al concepto indefinido y no legal de «neutralidad militar» no satisface las preocupaciones de los que votaron «no» en el referéndum sobre el Tratado de Lisboa en junio de 2008 con el fin de salvaguardar la neutralidad «activa». La declaración también afirma que «Será para Irlanda, en un espíritu de solidaridad y sin perjuicio de su política tradicional de neutralidad militar, para determinar la naturaleza de la ayuda o asistencia que debe proporcionarse a un Estado miembro que sea objeto de un ataque terrorista o víctima de una agresión armada en su territorio» (Devine, 2009). 
Si bien una porción de la población irlandesa se resiste a «ceder» su soberanía en aspectos de política exterior, seguridad y defensa, un mundo convulsionado frente a las nuevas amenazas hace necesario reevaluar su neutralidad. No obstante, esto se debe generar sin abandonar su apego a los principios del derecho internacional y de la Carta de las Naciones Unidas. Dado que Irlanda podría contemplar la posibilidad de consolidarse como un primer anillo de seguridad, tanto para Europa como para los Estados Unidos, puede, a partir de un fortalecimiento, lograrlo por la vía de cooperación de sus capacidades para proyección y control del mar. Ahora bien, lo anterior ocurre en con el acompañamiento de la OTAN, que desde el fin de la Guerra Fría se ha enfocado en apoyar la paz y se ha caracterizado por ser un defensor de los derechos humanos. En consecuencia, esto sería posible a partir del Programa de Asociación de la OTAN que ha llevado a la Alianza Atlántica a enfocarse en la cooperación. Esto es posible gracias a que dicha alianza no funciona como una calle de un solo sentido, sino que se caracteriza por su flexibilidad estructura de diálogo bilateral y multilateral, y por su naturaleza no discriminatoria.

A los países socios se les ofrece la misma base para las actividades de cooperación y conversaciones con la OTAN. Sin embargo, tienen la libertad de elegir el contenido y la intensidad de su compromiso con esta organización, en el pleno respeto del carácter de su política exterior (Novakovic, 2013).

\section{Política de Seguridad y Defensa Nacional: El Libro Blanco de 2015 T7}

El Libro Blanco de la Defensa Irlandesa, publicado en 2015, se convierte en la guía para el desarrollo de las actividades propias establecidas por el Gobierno para resguardar la soberanía y la supervivencia del país. Este documento está estructurado a partir de los escenarios previstos por el Gobierno irlandés a corto y mediano plazo, y tiene como base una forma de neutralidad liberal (mencionada anteriormente). Además, se apropia de los elementos militares, políticos, económicos y sociales del escenario internacional (Department of Defense, 2015).

Según el informe anual del Departamento de Defensa del año 2015, la política de defensa se enfoca en temas de emergencia, planificación de asuntos exteriores y comercio. Además, trabaja por mantener la paz mundial y el desarrollo continuo de la política común de la Unión Europea. Sin dejar de lado el multilateralismo ante la participación de la ONU y los compromisos con la alianza de la Paz de la OTAN y la OSCE, la estrategia de seguridad fue el tema de discusión por medio del Comité civil y militar conjunto. 
El Libro Blanco de Defensa establece entonces la política de defensa y tiene en cuenta la dinámica en temas de seguridad. Esto permite adaptarse a las situaciones cambiantes que se puedan presentar, como el apoyo a emergencias y al sostenimiento de la paz internacional. Así mismo, habla del mantenimiento y sostenimiento del personal, sin dejar de lado la importancia de mejorar las capacidades del personal de guardabosques.

El documento está dividido en 10 capítulos en los que se establecen las condiciones y situaciones que debe afrontar el gobierno irlandés. El documento contempla una amplia gama de escenarios, desde los análisis del entorno internacional y nacional, hasta la forma de su implementación. De esta manera, cubre con ellos los diversos elementos estructurales y de presupuesto necesarios para llevar a cabo sus metas.

Adicionalmente, el libro blanco estableció seis iniciativas principales que se describen a continuación. La primera de ellas trabaja el tema de ciclos fijos de defensa lo que permitiría planificación de defensa y provisión. La segunda realiza un estudio de financiación de defensa que proyecta el uso de los recursos a diez años gracias al ciclo fijo. La tercera destaca el trabajo conjunto con entidades gubernamentales con enfoque de género. La cuarta habla del desarrollo del instituto de la paz, entrenamiento y liderazgo con reconocimiento internacional para la solución de conflictos. La quinta menciona el compromiso en innovación e investigación motivando la iniciativa empresarial. Por último, la sexta habla de la creación de un nuevo plan de apoyo a las fuerzas de defensa, dirigido a personas entre 18 y 24 años (Department of the Taoiseach, 2018). Ahora bien, dentro de las muchas tareas asignadas a las Fuerzas de Defensa se encuentran la seguridad aeroportuaria y la protección para la zona pesquera. El servicio naval por su parte brinda un servicio de aduanas y apoyos a otros gobiernos con servicios de escolta. Por último, las Fuerzas de Defensas también cuentan con oficina de planificación de defensa.

\section{3,1 Seguridad y Defensa de Irlanda: actuación y evaluación del entorno internacional}

La política internacional de Defensa y Seguridad de Irlanda está definida por su constante apoyo a las Naciones Unidas (ONU). El sistema de preparación de la capacidad de sostenimiento de paz (PCRS), Sistema de Arreglos (UNSAS), la participación política Común de Seguridad y Defensa de la UE (PCSD) y la alianza para la paz de la OTAN (PFP). (Deparment of Defense and Defense Forces, 2015). Irlanda aplica la política común de seguridad y defensa (CSDP), como una parte 
de sus obligaciones con la comunidad extranjera de la UE para el sostenimiento de la paz y seguridad internacional.

Parte de ese esfuerzo se ve reflejado en las misiones actuales que desempeñan las Fuerzas de Defensa. En la Tabla 1 se encuentra una descripción de estas acciones.

Tabla 1. Misiones Internacionales de las Fuerzas de Defensa irlandesas

\begin{tabular}{|c|c|c|c|}
\hline $\begin{array}{l}\text { Misiones } \\
\text { actuales }\end{array}$ & Fecha & Descripción & Tipo de Misión \\
\hline MINURSO & $\begin{array}{l}\text { Septiembre } \\
\text { de } 1991 \text { hasta } \\
\text { la fecha. }\end{array}$ & $\begin{array}{l}\text { Despliegue de Cascos Azules como parte de } \\
\text { la misión de la ONU frente a la disputa del } \\
\text { Sahara Español entre Marruecos, Maurita- } \\
\text { nia, Algeria, Costa noroccidental } \\
\text { y el Océano Atlántico. }\end{array}$ & $\begin{array}{l}\text { Observadores de } \\
\text { misión para el } \\
\text { sostenimiento de } \\
\text { la paz (tres perso- } \\
\text { nas). }\end{array}$ \\
\hline MONUC & $\begin{array}{l}\text { Junio de } \\
2001 \text { hasta la } \\
\text { fecha. }\end{array}$ & $\begin{array}{l}\text { Misión de observadores como parte del con- } \\
\text { tingente enviado a la República del Con- } \\
\text { go, luego de la firma del tratado de Cese al } \\
\text { Fuego de Lusaka de } 1999 \text { y bajo } \\
\text { la Resolución } 1279 \text { de la ONU. }\end{array}$ & $\begin{array}{l}\text { Observadores } \\
\text { de misión para } \\
\text { el sostenimiento } \\
\text { de la paz (cuatro } \\
\text { personas). }\end{array}$ \\
\hline EUTM & $\begin{array}{l}\text { Febrero de } \\
2013 \text { hasta la } \\
\text { fecha. }\end{array}$ & $\begin{array}{l}\text {-Misión Militar establecida por el Consejo } \\
\text { Europeo para el entrenamiento de las Fuer- } \\
\text { zas de Seguridad de Mali. } \\
\text {-Contribución para el restablecimiento del } \\
\text { orden, la lucha contra el terrorismo } \\
\text { y crimen transnacional. }\end{array}$ & $\begin{array}{l}\text { Misión de entre- } \\
\text { namiento liderado } \\
\text { por la Unión Euro- } \\
\text { pea ( } 20 \text { personas). }\end{array}$ \\
\hline ISAF & $\begin{array}{l}\text { Diciembre de } \\
2001 \text { hasta la } \\
\text { fecha }\end{array}$ & $\begin{array}{l}\text { Como parte del Acuerdo de Bonn de } 2001 \\
\text { se crea el ISAF como una fuerza interna- } \\
\text { cional para asegurar la paz y la } \\
\text { estabilidad en Afganistán. }\end{array}$ & $\begin{array}{l}\text { Operaciones para } \\
\text { la protección de } \\
\text { la paz liderada } \\
\text { por la OTAN } \\
\text { (siete personas). }\end{array}$ \\
\hline $\begin{array}{l}\text { EUFOR/ } \\
\text { SFOR }\end{array}$ & $\begin{array}{l}\text { Mayo de } \\
1997 \text { hasta la } \\
\text { fecha }\end{array}$ & $\begin{array}{l}\text { Misión para la implementación de los } \\
\text { aspectos militares del Acuerdo de Paz de } \\
\text { Dayton sobre el fin de la guerra en Bosnia } \\
\text { - Herzegovina, bajo el mandato otorgado } \\
\text { a OTAN por la Resolución } \\
1031 \text { del Consejo de Seguridad de la ONU. }\end{array}$ & $\begin{array}{l}\text { Operación para el } \\
\text { manejo de crisis lid- } \\
\text { erada por la Unión } \\
\text { Europea (siete per- } \\
\text { sonas). }\end{array}$ \\
\hline KFOR & $\begin{array}{l}\text { Agosto de } \\
1999 \text { hasta la } \\
\text { fecha }\end{array}$ & $\begin{array}{l}\text { Misión para implementar los principios de } \\
\text { paz del G8 firmados por Serbia en } 1999 \\
\text { para Kosovo y amparados por la } \\
\text { OTAN bajo autorización } 1244 \text { del } \\
\text { Consejo de Seguridad de la ONU. }\end{array}$ & $\begin{array}{l}\text { Operación para } \\
\text { el sostenimien- } \\
\text { to de la paz } \\
\text { liderada por } \\
\text { la OTAN ( } 12 \\
\text { personas). }\end{array}$ \\
\hline UNDOF & $\begin{array}{l}\text { Junio de } \\
1997 \text { a agosto } \\
\text { de } 1998 \text { y } \\
\text { septiembre de } \\
2013 \text { hasta la } \\
\text { fecha. }\end{array}$ & $\begin{array}{l}\text { Misión de las Naciones Unidas amparada } \\
\text { por el Consejo de Seguridad de la ONU en } \\
1974 \text { para al cese de hostilidades entre tro- } \\
\text { pas israelíes y sirias en los Altos del } \\
\text { Golán. Ocurrida finalizada la Guer- } \\
\text { ra del Yom Kippur. }\end{array}$ & $\begin{array}{l}\text { Misión para el } \\
\text { sostenimiento de la } \\
\text { paz liderada por la } \\
\text { ONU (137 perso- } \\
\text { nas en tropas). }\end{array}$ \\
\hline
\end{tabular}




\begin{tabular}{|l|l|l|l|}
\hline \multicolumn{1}{|c|}{$\begin{array}{c}\text { Misiones } \\
\text { actuales }\end{array}$} & \multicolumn{1}{|c|}{ Fecha } & \multicolumn{1}{|c|}{ Descripción } & \multicolumn{1}{|c|}{ Tipo de Misión } \\
\hline UNFIL & $\begin{array}{l}\text { Mayo de } \\
1978 \text { hasta la } \\
\text { fecha }\end{array}$ & $\begin{array}{l}\text { Misión de restablecimiento de la paz y ob- } \\
\text { servación de repliegue de tropas } \\
\text { israelíes en El Líbano luego de la invasión } \\
\text { de 1978. }\end{array}$ & $\begin{array}{l}\text { Misión para el } \\
\text { sostenimiento de la } \\
\text { paz liderada por la } \\
\text { ONU (378 perso- } \\
\text { nas en tropas). }\end{array}$ \\
\hline UNNY & $\begin{array}{l}\text { Noviembre } \\
\text { de 1978 } \\
\text { hasta la } \\
\text { fecha }\end{array}$ & $\begin{array}{l}\text { Delegación de Oficiales de la Defensa ante } \\
\text { el Departamento de las Naciones Unidas } \\
\text { para Operaciones de Paz en las oficinas } \\
\text { centrales de Naciones Unidas en } \\
\text { Nueva York. }\end{array}$ & $\begin{array}{l}\text { Delegación de dos } \\
\text { oficiales }\end{array}$ \\
\hline
\end{tabular}

Fuente: Óglaigh na hÉiream. Defense Forces of Ireland.

Por otro lado, la garantía de expandir sus negocios con la Unión Europea, es coherente con su política exterior de defensa y su proceder interno. Las demás naciones aceptan y respetan su trabajo al fomentar relaciones económicas fuertes e intervenciones políticas en favor de su posición y su integridad como Estado independiente.

En cuanto a las amenazas externas, Irlanda, las aborda en su libro desde una perspectiva general. Con esto se evidencia su interés en prepararse para eventos como: la proliferación de armas y su distribución, la globalización vista desde los acuerdos comerciales, la libre circulación de bienes con fines económicos por transporte marítimo y el desarrollo económico en países emergentes. Otras temáticas que también son de su preocupación son el gasto de defensa de países como los Estados Unidos y China que permiten el aumento de sus capacidades militares, el cambio climático y la aparición de mayores inundaciones y cambios en los rendimientos de los cultivos (Ardila Castro \& Rodríguez, 2018). Las sequías, y desastres naturales causan inestabilidad regional y llevan a crisis humanitarias y económicas. Las emergencias migratorias también son preocupantes y el contrabando de migrantes como negocio rentable.

A esto se suman las problemáticas de la seguridad energética. En cuanto al suministro de energía para el año 2030, la Unión Europea deberá realizar la importación del $75 \%$ de la energía. Esto evidencia la escasez de recursos. Un agravante de la situación es el aumento en la seguridad alimentaria en el ámbito mundial. En cuanto a los avances tecnológicos, los problemas que se contemplan son la ciberdelincuencia y los ciberataques y el conflicto inter e intra estatal. Otros conflictos que se tienen en cuenta son el conflicto de bajo nivel por el acceso a los recursos, el terrorismo y sus acciones violentas para lograr sus objetivos por medio de asesinatos y daños a la población. En cuanto al espionaje hay preocupación por 
la obtención de información confidencial del Estado para fines militares de otros países. Otro de los retos por enfrentar es el crimen organizado transnacional que incluye el contrabando de drogas y de migrantes, la trata de personas, el lavado de dinero y la cibercriminalidad (Department of Defense, 2015).

\subsection{Evaluación del contexto interno}

En el trabajo de identificar las amenazas de seguridad y defensa que enfrenta el Estado, existe todavía una preocupación por actores armados internos proveniente del prolongado conflicto con el Ejército de Liberación Irlandés (IRA por sus siglas en inglés). A pesar de la firma de los Acuerdos de Paz del Viernes Santo, actores no conformes continúan creciendo y presentando nuevos desafíos para la seguridad. Cabe mencionar que el Estado y los actores no estatales tienden a combinar métodos asimétricos convencionales y de alta gama por tierra, mar, aire, y por el ciberespacio con la propagación de información. A esto se le conoce como guerra híbrida.

En el país hay un aumento de su preocupación por los desastres naturales, pues gracias a ubicación geográfica de Irlanda, podría enfrentar inundaciones, pandemias y enfermedades infecciosas en animales. Otra de las preocupaciones son los ciberataques que afectarían la infraestructura crítica del país, los servicios públicos, las entidades comerciales e incluso los individuos. Adicionalmente, existe preocupación por el dominio marítimo dado que, al ser una isla, fácilmente podría ser víctima de amenazas por mar (Department of Defense, 2015).

En respuesta a dichas amenazas internas y a futuras amenazas aún desconocidas, el Gobierno de Irlanda se prepara para dar una respuesta por medio de una política donde se establezcan roles principales y se centre en la formulación de su política de defensa en un papel de liderazgo.

\subsection{Funciones y misiones de las Fuerzas Armadas}

El gabinete privado del Ministro de Defensa está compuesto por el Jefe del Departamento de Defensa y ejerce control militar en el mando y en el ámbito ejecutivo y administrativo sobre las Fuerzas de Defensa en nombre del Gobierno. Entre sus responsabilidades están: servir de enlace entre el Ministro de Defensa y Ejército, asesorar al ministro en relación con su reunión ministerial, encargarse del proceso de correspondencia, representaciones y asuntos parlamentarios y consultas y organizar compromisos del Ministro. (Department of Defense, p. 2).

La rama del personal de las Fuerzas de Defensa está estructurada en la sección de personal y de reparación de injustos y en la sección de la fuerza de defensa de la reserva. (Department Of Defense, 2017, p. 11). 
También existe una oficina de proyectos del White Paper, de componente civil donde su objetivo principal es verificar que los proyectos derivados de este documento sean supervisados y apoyados por medio de la cooperación civil y militar. Dicho apoyo incluye la provisión de orientación y capacitación en relación con las técnicas y metodología.

Por esta razón, el Libro Blanco, en su Quinto Capítulo, establece las funciones de la Fuerza de Defensa de la Reserva o Reserve Defense Force $(\mathrm{RDF})^{21}$ y la Fuerza Permanente de Defensa o Permanent Defense Force (PDF) 22 , quienes forman parte de las Fuerzas Armadas Irlandesas. La RDF tiene cinco funciones, mientras que la PDF, tiene once para el cumplimiento de la misión.

Los cinco roles de la Fuerza de Defensa de la Reserva se resumen así: el primero, es la atención en situaciones de crisis, el segundo, es el apoyo en operaciones militares, el tercero, es el soporte en las tareas de seguridad en puertos (ATCP), el cuarto es el soporte a la autoridad civil (ATCA), y el quinto es la seguridad en el cuartel y apoyos para las tareas operativas. En temas que contribuyan al apoyo gubernamental, se estableció su participación en ceremonias militares (Department of Defense, 2015, p. 98).

Por otra parte, la Fuerza Permanente de Defensa en la actualidad tiene once funciones asignadas en el Libro Blanco de Defensa de la siguiente manera:

1. Ejecutar la defensa militar del Estado contra la agresión.

2. Participar en el apoyo de la paz multinacional, la gestión de crisis y las operaciones de socorro humanitario de conformidad con la dirección del Gobierno y la disposición legislativa (Libro Blanco pg. 59).

3. Ayudar al poder civil. Es decir, solicitar la ayuda de un Garda Siochána cuando sea necesario. Este tiene la responsabilidad principal de la ley y el orden, y también el de la protección de la seguridad interna del Estado.

4. Contribuir a la seguridad marítima que abarca la entrega de una pesquería en servicio de la protección y el funcionamiento del Centro Estatal de Vigilancia de la Pesca. Esto se hace en cooperación con otras agencias con responsabilidades en el sector marítimo para contribuir con una imagen operacional marítima compartida.

5. Participar en la interdicción del Grupo de Trabajo Conjunto sobre Drogas.

6. Contribuir a la resiliencia nacional por medio de la provisión de la defensa específica. Además, ayudar a la autoridad civil (ATCA) con el apoyo a las agencias líderes en respuesta a las principales emergencias, 
incluidas las emergencias de seguridad cibernética. Por último, apoyar al mantenimiento de servicios esenciales, tal como se establece en los Memorandos de Entendimiento y los Acuerdos sobre servicios acordados por el Departamento de Defensa.

7. Proporcionar un servicio de transporte aéreo ministerial (MATS).

8. Proporcionar servicios ceremoniales en nombre del gobierno.

9. Proporcionar una variedad apoyos a departamentos y agencias gubernamentales en línea con los MOU y los acuerdos sobre servicios acordados por el Departamento de Defensa. Entre estos se incluyen los servicios de búsqueda, de rescate y de ambulancia aérea.

10. Contribuir al bienestar económico de Irlanda a través del compromiso con la industria, la investigación y el desarrollo, y con iniciativas laborales, en apoyo de la política gubernamental.

11. Cumplir con cualquier otra tarea que el gobierno pueda asignar ocasionalmente (Libro Blanco pg. 59).

\subsection{Capacidades para dar aplicabilidad al Libro Blanco}

Irlanda se ha destacado desde su separación de Inglaterra, como un Estado soberano e independiente que busca su protección y reconocimiento en el ámbito internacional. Por esta razón, la creación del Libro Blanco de Defensa y Seguridad ha sido de gran importancia para la convivencia entre sus ciudadanos. La evolución de estos estatutos con el tiempo ha permitido conocer las posibles amenazas y planear como neutralizarlas (Department of Defense, 2015).

Desde un principio, el Libro Blanco buscó la creación de políticas que se especializaran en dos áreas centrales. La primera es la protección del Estado. Esto se traduce en que nada fomentará la guerra interna, y en caso de que esto ocurra, se debe tener la capacidad de reaccionar ante estos hechos. La segunda es la protección de las fronteras de tal forma que ninguna amenaza se acerque al territorio irlandés. Sin embargo, con el paso de los años, su visión de política de defensa y seguridad se ha expandido desde el fin de la Guerra Fría. Esto es debido a que han surgido otro tipo de amenazas para las cuales se debe estar preparado. Cabe resaltar que estas medidas están calculadas según el tamaño y capacidad del Estado y, por ende, de sus Fuerzas Militares (Department of Defense, 2015).

Desde entonces los enfoques principales con los cuales se ha expandido la visión de seguridad y defensa en Irlanda han sido varios, pero principalmente se destacan los siguientes: a. La seguridad como la piedra angular sobre las cual se construyen los valores culturales, sociales y económicos de una sociedad y b. La 
defensa que respalda la seguridad de Irlanda, así como a los intereses estratégicos del Estado en el entorno internacional.

La contribución de la defensa, dentro de un marco de seguridad más amplio, tiene el poder para decidir sobre el uso de activos de defensa hacia fines no relacionados con la seguridad. Estas decisiones también están encaminadas al uso de los recursos financieros de defensa y las capacidades para ser retenidas y desarrolladas, así como al manejo de asuntos relacionados con administración de defensa (Comisión de Seguridad Hemisférica, 2002).

Se puede establecer que la política de defensa es fundamental para el bienestar del Estado y sus ciudadanos, teniendo en cuenta que este país tiene historia llena de conflictos por subversión interna. Por ejemplo, en el ámbito internacional se reconoce otra gama de amenazas entre estas están el terrorismo, la proliferación de armas de destrucción masiva, los conflictos regionales, los fracasos estatales y el crimen organizado trasnacional y los conflictos internos. También se deben considerar las amenazas de evolución que las Naciones Unidas han mencionado como: ciberataques, seguridad energética, el cambio climático, la piratería, la seguridad marítima y la globalización por las relaciones comerciales entre los Estados (Comisión de Seguridad Hemisférica, 2002).

Para el país es importante aprender de las lecciones del pasado en el dominio de la seguridad y la ampliación de su rango de seguridad. Esto se refleja en la creciente interdependencia global con el crecimiento de amenazas tecnológicas y servicios que facilitan un negocio global. Dichas problemáticas solo se pueden solucionar con compromisos e instrumentos de política necesarios para su implementación.

\subsection{Capacidades de presupuesto}

En el ámbito de seguridad y defensa, Irlanda destina un 0,59\% de su PIB al gasto militar, esto es alrededor de 911 millones de Euros, ocupando el 18 lugar entre los 27 países de la Unión Europea. En cuestiones económicas y de financiación de seguridad y defensa de Irlanda se establece que el gobierno irlandés gasta menos de $1.5 \%$ del producto nacional bruto. Su gasto en defensa, como es un país pequeńo, no tiene la capacidad militar para establecer con consistencia una política exterior. Por esta razón, es reconocida como una neutralidad desarmada.

En la actualidad y, tras la recesión del año 2008, han surgido cambios en la política de seguridad y defensa por algunas restricciones financieras. Esto se ha reflejados en el gasto en defensa de 2015 , con un $20.8 \%$ menos que el gasto en 2008 y un $14 \%$ menos que en el año 2007 . El presupuesto no fue muy alto en 2012 y solo se necesitaron 9.500 personas para integrar la PDF. Para el año 2013 
se asignaron 4.069 personas para la RDF y de esta manera se trabajó en las fuerzas de defensa y de reserva para lograr una reorganización con el fin de maximizar la operatividad (Department of Defense, 2015).

Por otro lado, para la próxima década los problemas de capacidad se abordan con un enfoque flexible y receptivo y se establecen los principios claves en el desarrollo de la capacidad. Esto incluye la articulación de proyectos para la implementación y mejora en operatividad y efectividad del Ejército, el Cuerpo Aéreo y el Servicio Naval. De esta manera, se visualizan las prioridades en el caso de los fondos adicionales disponibles. Algunas estrategias propuestas en el Libro Blanco no se han puesto en marcha por la falta de recursos económicos. Sin embargo, esto no ha afectado el desarrollo de sus relaciones diplomáticas. El país ha podido sobrellevar las necesidades de su seguridad al igual que las alianzas económicas que resaltan su neutralidad.

En cuanto a la asignación de gastos de capital, el Ministro de Defensa, Paul Kehoe, anunció que el presupuesto para el año 2018 contó con un aumento de 25 millones de Euros, cerca de 98 millones más en comparación con lo asignado en el año 2017. Este dinero se sumará a los fondos de capital para el periodo 2018-2021. Esto se hace con el fin de cumplir con los compromisos del Libro Blanco tanto en el país como en el extranjero (Department of Defense, 2017).

Entre los destinos de este dinero está el de mejorar la gama de equipos de defensa y la infraestructura de las fuerzas de defensa de Irlanda. Esto permita un impulso significativo para lo modernización y mejoramiento de los equipos de defensa.

El Gráfico 1 ofrece una comparación entre los gastos de defensa de 2017 con los de 2018.

Financial Overview

Gross Estimates - Vote 36 (Defence) and Vote 35 (Army Pensions)

\begin{tabular}{|c|c|c|}
\hline & $\begin{array}{c}2017 \\
\mathrm{fm}\end{array}$ & $\begin{array}{c}2018 \\
\mathrm{~cm}\end{array}$ \\
\hline Vote 36 (Defence) & 692 & 707 \\
\hline Vote 35 (Army Pensions) & 229 & 239 \\
\hline Overall Gross $(\mathrm{cm})$ & 921 & 946 \\
\hline
\end{tabular}

Gráfico 1. Costos de la estructura de Defensa

Fuente: Deparment of Defense 
En cuando a la a asignación bruta asignada al sector de defensa, en el año 2018 es de $€ 946$ el cual comprende $€ 707 \mathrm{~m}$ para defensa (Voto 36) y $€ 239 \mathrm{~m}$ para pensiones del Ejército (Voto 35). Unos 509 millones de Euros del Voto de defensa estipulan los sueldos y prestaciones de más de 10.400 empleados del servicio público, que comprenden a 9.500 empleados de la Fuerza de Defensa Permanente, 550 empleados civiles y 355 funcionarios. Esta adjudicación incluye el compromiso de Lansdowne Road o Servicio público de estabilidad 2018-2020 de unos 12 millones de Euros. Esta distribución financiera facilitará el reclutamiento continuo y el Ministro ha reafirmado su compromiso de lograr que Fuerza de Defensa Permanente alcance un nivel de 9.500 (Department of Defense, 2017).

La asignación no remunerada de 198 millones de Euros para la defensa (incluidos 77 millones de Euros en capital) cubre principalmente los costos operativos y de funcionamiento de las Fuerzas de Defensa esenciales. Esto incluye la adquisición y actualización necesarias de equipos e infraestructura defensivos. El Programa de Reemplazo de buques navales continúa con la incorporación a la flota del cuarto buque Lé George Bernard Shaw. Este barco está programado para entregarse a mediados de 2018 a un costo de unos 67 millones de Euros.

Los 98 millones de Euros adicionales en fondos de capital de defensa lo elevan a 416 millones de Euros durante el período 2018-2021. Esta asignación proporciona el reemplazo de la flota de Cessna con tres aeronaves más grandes adecuadamente equipadas para tareas de inteligencia, vigilancia, adquisición de objetivos y reconocimiento. La competencia de licitación para la adquisición de los tres nuevos aviones está en marcha. El proceso de adquisición para el reemplazo de los dos aviones de la Patrulla Casa Marítima comenzará en 2018. También se establecen fondos para comenzar el proceso de adquisición de un Buque Multi-Role para reemplazar al Lé Eithne. Adicionalmente, el Voto de defensa también incluye fondos para la Fuerza de Defensa de la Reserva, Defensa Civil y una donación a la Sociedad de la Cruz Roja Irlandesa.

Con respecto al Voto de pensiones del Ejército, hay más de 12.300 pensionistas militares pagados por el Departamento de Defensa. El gasto de las pensiones del Ejército es en gran medida no discrecional y está impulsado por la demanda. La provisión para 2018 aumentará en 10 millones de Euros a unos 239 millones de Euros. Este aumento se debe principalmente a un número creciente de pensionistas del Ejército.

La asignación para 2018 incluye fondos para inversiones significativas en la infraestructura construida por las Fuerzas de Defensa, incluidos los siguientes proyectos: 
- Mejora del almacén de almacenamiento seguro (municiones), DFTC.

- Rehabilitación del Bloque de Bloques, Cuartel de Cathal Brugha.

- Mejora de alojamiento (Barracas de Pearse), DFTC.

- Equitation Stables Re Roofing, McKee Barracks.

\subsubsection{ESTRUCTURA MILITAR DE LA DEFENSA}

Las Leyes de Defensa de 1954 a 2015 proporcionan la base legislativa para las Fuerzas de Defensa. En al capítulo II, el Artículo 18, establece que existirá una Fuerza de Defensa (PDF) y una Fuerza de Defensa de Reserva (RDF) que tendrán componentes militares, navales y aéreos (eISB, 1954).

Irlanda forma parte de la Unión Europea desde el año 1973. También forma parte de las Naciones Unidas desde el año 1955 y a su vez de distintas organizaciones regionales de Europa como el Consejo de Europa. No pertenece a la OTAN por ser un Estado neutral ni a la Commonwealth.

Aunque Irlanda es un país neutral, desde la Segunda Guerra Mundial, cuenta con unas fuerzas armadas pequeñas pero capacitadas y equipadas. Las Fuerzas de Defensa Irlandesas (Óglaigh na Héireann, en gálico) están compuestas por la Marina, la Fuerza Aérea y la Fuerza de Reserva (Academic, 2018).

Se recuerda que la estrategia impuesta por el Banco Europeo y por el Fondo Monetario Internacional para lograr el rescate económico que Irlanda necesitó durante su crisis en los años 2008-2013 fue la reducción de Las Fuerzas de Defensa Irlandesas. Por esta razón, las Fuerzas Armadas quedaron compuestas de la siguiente manera:

\section{Ejército de Irlanda}

El Ejército Irlandés lo componen 8.500 personas y 14.000 sumando la reserva. El Estado se divide en tres brigadas divididas en norte, centro y sur. Este tipo de estructura de brigadas divide el trabajo operacional en distintas responsabilidades. La primera está a cargo de los asuntos en relación con las fronteras, la segunda se encarga de las ciudades de Dublín y Leinster, y la tercera se encarga de las zonas de Munster y Connacht. Además, cuenta con un centro de entrenamiento militar, una base de logística y varias bases con fines militares. El Ejército de Irlanda se encuentra conformado por dos brigadas, una fuerza de defensa y un centro de reentrenamiento para el personal militar. Su principal función es proporcionar las capacidades primarias para operaciones militares y desarrollar las operaciones de apoyo de paz en el exterior. 
El Ejército irlandés está compuesto por los cuerpos de infantería, caballería, artillería, ingenieros, médico, transporte, policía militar y comunicaciones y servicios, quienes garantizan la seguridad de la isla. El Batallón de Infantería está compuesto por tres compañías de fusileros, una compañía de apoyo y una empresa que administra los elementos logísticos y de comunicaciones necesarias para la ejecución de las operaciones (ver Gráfica 2). Esto existe con el fin de preservar la seguridad de la isla, la paz y la seguridad internacional.

\section{Armada de Irlanda}

La marina cuenta con 1.144 personas que cumplen funciones similares a las del Ejército, además de proteger la vida marina en la «Caja de Conservación Irlandesa». Esta comprende una reserva marina en la cual la pesca está prohibida con el fin de preservar su fauna y flora. Sus principales funciones son la protección de la industria pesquera, ayudar a los civiles, interceptar de drogas y mantener la seguridad marítima (Defensa, 2018).

La organización del Servicio Naval, la cual está conformada por el Comando de Operaciones Navales, quienes se encargan de realizar todas las operaciones a flote y tierra y las operaciones con buques del Servicio Naval (Óglaigh na Héireann, 2018), asi como el Comando de Apoyo Naval (Naval Support Command), quien tiene la tarea de mantener el servicio naval en el cumplimiento de sus funciones. Este se compone de cuatro departamentos: Support HQ, Unidad de Ingeniería Mecánica y Astillero Naval, Departamento Logístico y la Unidad Eléctrica de Armas.

El Support HQ, está conformado por el PSM, el cual es responsable de todos los asuntos de personal, políticas, asesoramiento de asuntos de personal, reclutamiento, mantenimiento de registro de personal, pago y servicios médicos. Entre ellos se encuentra la planificación de inspección y mantenimiento, se encarga de elaborar las normas técnicas de la sección de gestión de mantenimiento y planificación e inspección. La Unidades de Ingeniería Mecánica y Astillero Naval (Mechanical Engineering and Naval Dockyard Unit), son las encargadas de realizar el soporte técnico de los barcos de servicio naval; se encuentran divididas en las secciones de Plantas y Maquinaria y Astilleros Navales.

Por otra parte, el Departamento Logístico Base (Base Logistics Department), se encarga del abastecimiento y de la adquisición de provisiones, del mantenimiento de las tiendas navales y las de ropa. Está compuesto por tres secciones: la Sección de Alojamiento y Mesetas, la Sección de Mantenimiento de Ingeniería y la Sección de Transporte por carretera. 
Por otra parte, de la unidad eléctrica de armas (Weapons Electrical Unit), es la encargada de coordinar y controlar el trabajo de componentes. Está dividida en la Sección Técnica de Comunicaciones, la Sección Eléctrica y Electrónica y la Sección de Artillería.

Como se observa en el Gráfico 2, el Comando de Operaciones Navales (Naval Operations Command), tiene la tarea de llevar a cabo las operaciones a flote y en tierra por el servicio naval. Se divide en cuatro diferentes secciones: HQ de operaciones, Sección de Inteligencia y Pesca, Forst y Operaciones en tierra.

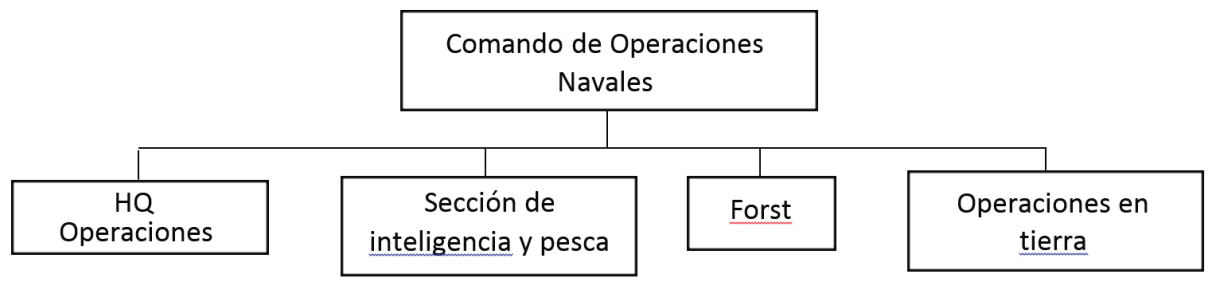

Gráfico 2: Estructura Comando de Operaciones Navales

Fuente: Tomado y adaptado de la página web: http://www.military.ie/naval-service/organisation/ naval-operations- command/

\section{Fuerza Aérea de Irlanda}

De las ramas de las Fuerzas de Defensa de Irlanda, la Fuerza Aérea es la más pequeña porque cuenta con menos de mil efectivos y la cantidad que tiene de aeronaves no tiene la capacidad de reacción para proteger todo el territorio irlandés. Sus principales funciones son: apoyar a las otras ramas que componen las Fuerzas de Defensa, apoyar la comunidad civil y vigilar desde el aire las aguas territoriales de Irlanda. La Fuerza Aérea de Irlanda cuenta con Operaciones de Ala nro. 1. y actualmente opera con nueve aviones y se encarga de realizar el mantenimiento de las aeronaves de primera línea y de las asignadas. Las Operaciones de Ala nro.3, lleva acabo todas las tareas de alas giratorias, opera con ocho aviones, con seis Augusta Westland AW139 y dos Eurocopter EC-135. Por otra parte, existen los soportes del Ala nro. 4, la cual realiza mantenimiento de segunda línea, adquisición y gestión de repuestos y gestiona gestión el combustible y el soporte de Ala nro ${ }^{\circ} 5$. Además, es responsable de realizar el apoyo logístico y se divide en seis escuadrones de apoyo separados.

El cuerpo aéreo (Air Corps Head Quarters), está compuesta por secciones de apoyo de esta manera: Sección de Operaciones, Secciones Especializadas, Secciones de Seguridad de Vuelo, y la Sección de Policía Militar. Estas secciones se encargan de la planificación estratégica de la gestión, el control y planificación operacional, 
las relaciones públicas y la aeronavegabilidad de los aviones que están en servicio del cuerpo aéreo.

El Escuadrón de Servicios de Comunicación e Información (Communication \& Information Services Squadron), se ocupa de los sistemas y comunicaciones, y de la navegación e información requerida por Fuerza Aérea. A su vez, está dividida en la Sede Escuadrón de CIS46, Vuelo de los servicios del Aeródromo, Vuelo de Comunicaciones, Vuelo de servicios técnicos y Vuelo de tecnología de la información.

El Libro Blanco de la Republica Irlanda deja claro que es un Estado neutral no beligerante. Esta es la razón por la cual sus Fuerzas Armadas o Fuerzas de Defensa son pequeñas en comparación con otras fuerzas armadas europeas. Indudablemente, Irlanda tiene la capacidad de proteger y mantener la paz en su territorio y puede participar en distintas operaciones en las que la ONU requiera su ayuda, especialmente en el apoyo humanitario y la preservación de la paz (Libro Blanco Irlanda, 2012).

\subsection{Capacidades de seguridad y defensa para el desarrollo}

Luego de las críticas realizadas al concepto de seguridad, se creó un nuevo concepto que se describe a continuación:

«La seguridad toma una perspectiva multidimensional en la que se asume que
además de las amenazas militares hay otras amenazas (económicas, medioambien-
tales, migraciones masivas, etc.), que las mismas son transfronterizas y globales,
que vivimos en un mundo interdependiente y que, por tanto, las estrategias para
abordar esa nueva realidad no pueden ser las estrictamente militares, sino que hay
que introducir estrategias diplomáticas, civiles, policiales y de cooperación al desa-
rrollo, entre otras. Esta nueva visión se ha ido desarrollando desde finales de los
ochenta y ha culminado en la primera década del siglo XXI en las nuevas doctrinas
de seguridad» (Font \& Ortega, 2010).

Por esta razón, el Gobierno irlandés elaboró un documento denominado Estrategia 2017-2020, en el que establecen prioridades estratégicas. Mediante las acciones encaminadas a reformar y mejorar la confianza en las instituciones del Estado y asegurar que los errores que llevaron a la crisis económica no se repetirán, se define la primera estrategia llamada «apoyo al Taoiseach y al Gobierno» (Support the Taoiseach and Government). Esta estrategia se ejecuta apoya al gobierno en temas de política interna y asuntos internacionales, y tiene en cuenta las voces de los más jóvenes y de las mujeres (Fernandez-Osorio \& Latorre-Rojas, 2018). 
En segundo lugar, se encuentra el interés por trabajar en una «economía Sostenible» (Sustainable Economy). Con esta estrategia se trabaja por mejorar las condiciones de empleo, crecimiento de las finanzas y las empresas, el comercio e inversión, la vivienda, la infraestructura y el desarrollo de la región. Esto se propone con el fin de buscar una política macroeconómica y fiscal, mayor competitividad, mayor inversión y mejorar el comercio, exportaciones y turismo.

La tercera estrategia política menciona «Una sociedad mejor y justa» (a better fairer society). Su propósito es el de garantizar las políticas y servicios del Gobierno donde la participación sea justa. También se propone la reforma a la salud, educación, justicia y otros servicios. El Estado seguirá ayudando al Servicio Civil para que brinde mejores servicios a sus ciudadanos. Este punto es de vital importancia para garantizar comunicaciones simples, con las se perciba la presencia en diferentes lugares de la sociedad. La educación, por su parte, pretende alcanzar beneficios para lograr mejores resultados. Estas iniciativas buscan mejorar el desarrollo de la política social (p.10)

En temas de internacionalización, se habla en cuarto lugar de la «fuerte relación en Europa y el Mundo" (Strong Relationship in Europe and the World). En este aspecto se resalta la importancia de mantener buenas relaciones con sus vecinos. Para ello se pretende desempeñar un papel pleno y efectivo en todos los aspectos de los acuerdos con la Unión Europea, en protección los intereses políticos y económicos de la nación. Con el fin de aumentar la inversión extranjera, se buscará mantener las buenas relaciones con las naciones del Mundo mediante el aumento de sus misiones diplomáticas (p.11).

El quinto lugar es relación con el Brexit, Irlanda busca mejorar los resultados en estas cuatro prioridades: el comercio, la economía, el proceso de paz y el futuro de la Unión Europea. De esta manera, el interés se enfoca en la implantación de las garantías adquiridas y la ampliación de la conciencia frente los problemas y los desafíos de las partes interesadas. Así mismo, se continuará con el trabajo por la paz, la reconciliación y el cumplimiento de los Acuerdos del Viernes Santo. Esto incluye trabajar por la restauración de las instituciones (Department of the Taoiseach, 2018).

Por último, Irlanda trabajará en «planear hacia el futuro» (Planning for future). Con este propósito, Irlanda proyecta ser competente en tecnología, comercio, inversión y moverse según los cambios en la Unión Europea. Para ello pretende mejorar en competitividad y mantener altos estándares de vida e infraestructura entre ellos vivienda, banda ancha, atención médica, educación, transporte, energía y agua. Por otro lado, Irlanda planea trabajar en la implementación de los compromisos internacionales sobre el cambio climático, el desarrollo sostenible y la protección 
del medio ambiente. Por último, pretende implementar las políticas de migración, atender los desafíos demográficos de financiación, educación y reformas de salud (Department of the Taoiseach, 2018).

En el año 2014, el departamento de Taoiseach publicó la evaluación nacional de riesgos, e identificó que los riesgos tanto financieros como no financieros podrían tener un impacto adverso en el bienestar de Irlanda. Esto le llevó formular planes para asegurar que existan marcos apropiados de prevención y mitigación para abordar los riesgos nominados. Todo esto se propuso con el objetivo de evitar ataques terroristas, pandemias, desastres naturales o financieros. El ámbito regional e internacional se avanza para ampliar la evaluación de riesgos del enfoque tradicional que abarcan factores económicos y sociales más amplios (Department of Defense, 2015).

A partir de estos dos enfoques, la neutralidad como política exterior de defensa y los requerimientos de protección de riesgos en el ámbito nacional, se evidencia que estas son insignias de lo que ha representado su historia. Además, sus proyecciones geoestratégicas responden a sus intereses nacionales de constituirse como nación fuerte con soberanía y estándar internacional.

\section{De Irlanda a Colombia: algunos elementos de reflexión}

Hasta este punto, el presente trabajo ha revisado los elementos centrales y relevantes expuestos dentro del Libro Blanco de la Defensa Irlandés. Este documento ofrece elementos de análisis por ser factores de referencia para el caso de Colombia y la construcción su de Libro Blanco de Defensa. Si bien es cierto que las condiciones históricas, políticas, sociales, económicas y militares de ambos Estados tienen considerables diferencias, existen puntos comparables que permiten considerar experiencias para el aprendizaje.

Cabe rescatar en primer lugar, la situación de neutralidad en la actuación internacional. Esta cuestión se ha desarrollado ampliamente al inicio de este documento. Como se ha mencionado, Irlanda conserva este estatus neutral, y este se relaciona estrechamente con central de su Constitución Política. Se puede afirmar que la condición de neutralidad de Irlanda está atada no solo a la Cata Magna, sino también a consideraciones sociales, políticas e históricas, y al hecho de que dicha condición se relacione con su vinculación a organizaciones como la Unión Europea, la OTAN y con el desarrollo de Operaciones de Paz de Naciones Unidas. 
Si bien se parte del concepto de neutralidad ejemplificado por Irlanda, los elementos centrales para encontrar una relación con Colombia no tienen que ver estrictamente con la condición de neutralidad, sino con elementos como la visión constitucional de respeto por las normas internacionales y la posibilidad actual de participar de forma activa en las Operaciones de Paz en el marco de las Naciones Unidas (Fernandez-Osorio, 2017).

En relación con lo anterior, lo consagrado en el Artículo 9 de la Constitución Política de Colombia, no difiere mucho en la intencionalidad y alcance de lo consagrado en el Artículo 37 de la Constitución de Irlanda de 1937. En ambas consideraciones prima el respeto a la autodeterminación de los pueblos y el respeto y reconocimiento de los principios del Derecho Internacional. Frente a la segunda condición, la experiencia de las Fuerzas de Defensa Irlandesas representa un punto de referencia para Colombia, no solo en términos del uso de tropas sino en cuanto al comportamiento general en diversos contextos. Se recuerda que las IDF, tienen una amplia experiencia en el desarrollo de operaciones de paz dentro de la UE y Naciones Unidas en Europa y África. Dichas experiencias merecen ser tomadas como referentes toda vez que sea la intención de Gobierno y de las Fuerzas Militares (FFMM) colombianas participar en Misiones de paz de Naciones Unidas y como socio internacional de la OTAN suscrito por Colombia.

Otro de los elementos que merece de atención es el tema del manejo y evaluación del contexto interno. En cuanto a aspecto es necesario indicar que, pese que las condiciones de conflicto interno vividas en Irlanda con el IRA, su dinámica difiere en muchos aspectos con la situación de conflicto interno que vivió Colombia con las FARC. Se puede asegurar que, durante la existencia de ambos grupos como organizaciones armadas, hubo conexiones entre ellas (Redacción Jurídica e Internacional, 2001). Por otra parte, frente a los acuerdos que darían paso al posconflicto tanto en Irlanda como Colombia, se han presentado disidencias que buscan mantener una visión ideológica enfocada a mantener una situación de conflicto. Ejemplos respectivos de lo anterior son, en Colombia, las disidencias de las FARC formadas después de la firma del Acuerdo de La Habana y en Irlanda, las de disidencias del IRA como el Nuevo Ejército Irlandés (NIRA por sus siglas en inglés) y la Continuidad del Ejército Irlandés (CIRA por sus siglas en inglés) (Central Intelligence Agency, 2018) ; Torrijos Rivera \& Abella Osorio, 2018).

En este último escenario es necesario recordar que el presidente de Irlanda, Michael Daniel Higgins, visitó Colombia y estableció una reunión con su homólogo Juan Manuel Santos. Durante esta visita se firmaron varios acuerdos y se visitó una de las zonas de agrupamiento de las FARC (Colombia.com, 2017). En 
algunos de los acuerdos se propuso el programa de apoyo que adoptó el Gobierno de Irlanda en temas relacionados con las lecciones aprendidas en el proceso de paz y así mismo se trataron temas de cooperación para el apoyo al posconflicto que adelanta Colombia.

El último tema que amerita una revisión comparativa entre los dos países radica en la estructura, funcionamiento y presupuesto de sus Fuerzas Militares. Esta es una cuestión central qua ayudará a identificar elementos claves en el adecuado funcionamiento y en la proyección de la fuerza para el caso colombiano.

En un apartado anterior se han mencionado los principales elementos de la organización de las Fuerzas Armadas de Irlanda, sus funciones y los elementos presupuestales para su funcionamiento. Este último punto resulta relevante en el sentido que la estructura y funcionamiento de las Fuerzas Militares irlandesas han sido revisados a la luz de los acuerdos con la UE en respuesta a la crisis económica por la que atravesó Irlanda el año 2008. Como bien se mencionó, el presupuesto para las Fuerzas Militares de Irlanda equivale al 0,59\% del PIB. Gran parte de dichos recursos está destinado al funcionamiento y pago de pensiones, lo que deja muy poco espacio para la inversión y compra de armamento (Department of Defense, 2015, p. 115-118).

Una situación similar ocurre en Colombia en el sentido del destino final del presupuesto asignado a sector defensa. Si bien es cierto que, a diferencia de Irlanda, Colombia destina cerca del $3.3 \%$ del PIB $^{54}$ para temas de defensa y policía, también es cierto que gran parte de ese presupuesto asignado está destinado a temas de funcionamiento y pago de pensiones del personal del sector.

Para el caso de Colombia, del presupuesto asignado, tanto en 2017 y 2018, entre el $97 \%$ y el $98 \%$ está destinado para gastos de funcionamiento. Esto deja tan solo una porción para temas de inversión (Ministerio de Hacienda, p. 18-21).

Frente al escenario del tamaño y estructura de las Fuerzas Armadas de ambos países, existe una notable diferencia. Para el caso de Irlanda y como se mencionó con anterioridad, las Fuerzas de Defensa están compuestas por el Ejército, el Cuerpo Aéreo, la Armada y las Tropas en Ultramar (generalmente en misiones de paz de Naciones Unidas y de la UE). Si bien es cierto que no hay datos concretos sobre el tamaño del Ejército, se sabe que el Cuerpo Aéreo tiene 750 hombres, la Armada 1.144 y el componente de cascos azules cerca de 570 hombres. Un estimado sobre el total de hombres de las Fuerzas de Defensa estaría cerca de los 9.000 a 9.500. Los mayores componentes del ejército son dos brigadas y el Centro de Entrenamiento (Óglaigh na Héireann).

Caso contrario ocurre en el caso colombiano. Las fuerzas están distribuidas en cuatro instituciones principales a saber: Ejército, Fuerza Aérea, Armada e Infantería 
de Marina. Frente al tamaño de las tropas de cada una de las fuerzas, se ha notado un crecimiento acorde con las necesidades de seguridad y defensa del país. Sobre esto se ha hablado extensamente en medios de comunicación y portales especializados en el tema. Sin embargo, según los datos del Banco Mundial en2016, el total de personal de las Fuerzas Armadas en Colombia era de 481,100 hombres, sin llegar a especificar la cantidad de personal por fuerza o sin definir el número del personal civil (The World Bank). En el Gráfico 3 se ilustra el crecimiento del personal en las Fuerzas Armadas de Colombia en los últimos ańos.

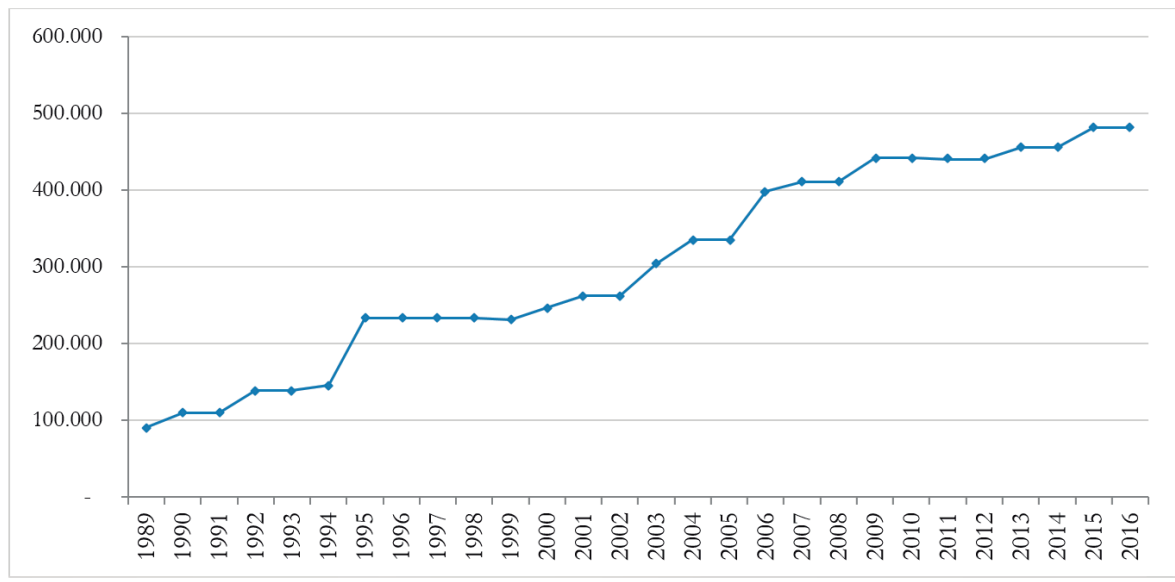

Gráfico 3. Total de personal Fuerzas Armadas de Colombia (Ejército, Armada, Fuerza Aérea y Policía Nacional)

Fuente: Datos Tomados del Banco Mundial

Otro de los aspectos que bien vale la pena revisar, es la condición y desarrollo del Libro Blanco de Irlanda, la funcionalidad de las Fuerzas de Defensa para atender situaciones de desastre y el apoyo a las autoridades policiales de ser requeridas. Este elemento, señalado inicialmente en el Capítulo 5 del Libro Blanco y desarrollado en capítulos posteriores de dicho documento, da a entender que los roles de las Fuerzas de Defensa pueden llegar a tener lugar en el contexto interno como apoyo y soporte a las autoridades civiles, y en la contribución al desarrollo económico del país (Department of Defense, 2015, p. 59).

En el caso de Colombia, las FFMM han tenido un rol central el escenario interno, no solo en relación con los actores violentos, sino también en acciones de apoyo a autoridades civiles, atención de desastres, rescate y evacuación de personal, entre otras.

Ahora bien, un documento donde se definen claridad estos roles es la Política de Seguridad. Para efectos prácticos nos referiremos a la desarrollada para el periodo 
2015-2018 del Presidente Juan Manuel Santos. En ella se establecen los elementos claros para disponer de los recursos militares para temas como la mitigación del cambio climático y atención de desastres. Dichos temas fueron desarrollados en la sección 4.8 y 4.9 de la Política de Defensa y Seguridad Todos por un Nuevo País (Ministerio de Defensa Nacional, 2015, p. 30-33)-

\section{Conclusiones}

El estudio de los Libros Blancos de Defensa no solo es relevante, sino necesario para la comprensión de las visiones establecidas por los diferentes países sobre los temas de seguridad y defensa. Dichos documentos, al ser de carácter estratégico, reúnen los principales elementos relacionados en los diferentes temas que tienen que ver con la supervivencia del Estado. De esta forma se convierte en una guía donde se consignan las principales directrices con miras a proyectar y defender los intereses estatales. Si bien es cierto que el Libro Blanco centra su visión en la estructura y capacidades militares de un país, no se abstiene de relacionarse con temas económicos, políticos y sociales relevantes para construir un documento holístico y completo sobre las realidades y desafíos a las que se tiene que enfrentar un país en un periodo determinado.

En el desarrollo de este capítulo resultó de gran interés conocer la perspectiva irlandesa sobre los temas de defensa y seguridad, a partir de una revisión de elementos históricos relevantes y de la construcción de una visión única sobre su defensa y accionar en el escenario internacional. Desde el punto de vista histórico, la construcción de la identidad en Irlanda tiene que ver estrechamente con su relación con el Reino Unido y con su posterior vinculación a la Unión Europea. Dicha construcción identitaria es fundamental en la formación de la una visión única y singular de neutralidad no armada para su estabilidad como Estado.

En lo referente a la visión de neutralidad no armada de Irlanda, es necesario comentar que, a pesar de establecerse como un principio constitucional, esto no significa que Irlanda no participe o forme parte de escenarios multilaterales como la Unión Europea, las Naciones Unidas, la OTAN, entre otras.

Su visión de la neutralidad radica en no participar como fuerza armada en operaciones de seguridad en el ámbito internacional, pero sí en misiones de paz o de sostenimiento de la paz, como se evidenció ampliamente. Por otra parte, su visión de neutralidad es también fundamental ya que al ser parte de la UE y de la OTAN, garantiza la defensa de su territorio. Estos acuerdos de seguridad internacionales le permiten compensar su poca capacidad militar. 
Es importante resaltar que para Irlanda tiene un amplio conocimiento de su entrono estratégico. Por esta razón establece que tanto su defensa como su seguridad no radican solo en los temas militares. Irlanda considera en su visión de seguridad los temas económicos, políticos y sociales como relevantes. De la misma manera, incluye en su evaluación temas como el terrorismo, el cambio climático y los efectos de la globalización.

Ahora bien, frente al escenario de Colombia, hay elementos significativos que se pueden rescatar y de alguna forma aplicar en el país. El punto central de reflexión parte necesariamente de la construcción y desarrollo de un Libro Blanco de Defensa en Colombia, cuestión que en la actualidad es inexistente pese al desarrollo de políticas de seguridad.

Dicho documento es necesario para definir las acciones y directrices, y además para identificar los escenarios y desafíos a la seguridad y defensa del país.

Uno de los puntos es relevante como experiencia para Colombia es el manejo que Irlanda ha dado a su participación en misiones internacionales de paz. La experiencia de Irlanda en 60 años de participación en este tipo de misiones bajo el liderazgo de las Naciones Unidas, la EU y la OTAN en diferentes partes del mundo, debe ser un referente para nuestro país. Esto se hace evidente por la clara intención de tener un contingente de tropas colombianas que puedan ser desplegadas bajo este tipo de misiones.

Otro de los aspectos que también se deben tener en cuenta es lo relacionado al manejo y experiencias en temas de posconflicto. Si bien es cierto que el surgimiento del grupo IRA tuvo mayor acción el Irlanda del Norte, muchos de sus efectos también se sintieron en Irlanda y siguen siendo considerados como elementos importantes en la seguridad interna. En este sentido, la visita Primer Ministro de Irlanda a Colombia se enfocó en el apoyo a los acuerdos de Paz y en la visión hacia un posconflicto que conduzca a un escenario de paz permanente.

Por último y no menos importante, es necesario resaltar que, tanto para el caso de Irlanda como para el caso colombiano, los gobiernos han considerado que sus Fuerzas Militares, además de ser las encargadas de velar por la defensa de la soberanía del Estado, también tengan asignadas funciones que trascienden de lo militar. Esto se traduce en acciones de apoyo a otras entidades de los Estados. Se ha demostrado como las Fuerzas Militares en su amplio accionar también son capaces de reaccionaren situaciones de desastre y de apoyar el desarrollo económico de los países. 


\section{Referencias}

(s.f.). Recuperado el 5 de junio de 2018, de Constitución de Irlanda: http://www.concourt.am/armenian/legal_resources/world_constitutions/constit/ireland/irel nd-s.htm

Academic. (29 de enero de 2018). Academic. Obtenido de http://www.esacademic.com/dic.nsf/ eswiki/318870

Alonso, R. (2001). Irlanda del Norte «Una Historia de la guerra y la búsqueda de la paz». Madrid: Complutense.

Álvarez Calderón, C., \& Rodríguez Beltrán, C. (2018). Ecosistemas criminales. Revista Científica General José María Córdova, 16(24), 1-30. https://doi.org/10.21830/19006586.352

Andrews, B. (2 de enero de 2018). The Irish Time. Recuperado el 3 de enero de 2018, de EU defence co-operation is no threat to Irish neutrality: https://www.irishtimes.com/opinion/eu-defence-cooperation-is-no-threat-to-irish- neutrality-1.3343293

Ardila Castro, C., \& Rodríguez, J. (2018). Visión geoestratégica china y su incidencia sobre Latinoamérica y África. Revista Científica General José María Córdova, 16(23), 1-22. https:// doi.org/10.21830/19006586.303

Borges, Mariana. (Noviembre de 2016). Irlanda pelo mundo. Um guia feito por uma jornalista.

Rio de Janeiro, Brazil: Coast Road, Galway.

Central Intelligence Agency. (8 de abril de 2018). CIA The World Factbook. Recuperado el 13 de abril de 2018, de Ireland: https://www.cia.gov/library/publications/the-world- factbook/geos/ei.html

Clauso, A. (1993). Análisis Documental: el análisis formal. Revista General de Información y Documentación, (p. 11-19).

Colombia.com. (11 de febrero de 2017). El presidente de Irlanda visita Colombia para apoyar el posconflicto. Recuperado el 7 de enero de 2018, de http://www.colombia.com/actualidad/nacionales/ sdi/150997/el-presidente-de-irlanda- visita-colombia-para-apoyar-el-posconflicto

Cruset, M. E. (2011). El Acuerdo de Viernes Santo en Irlanda del Norte y su realidad hoy. Revista Contemporánea, (p. 78-93).

David, C. (2008). La Guerra y la Paz. Enfoque Contemporáneo sobre la seguridad y la estrategia (primera edición ed.). Barcelona: Icaria Editorial.

Defensa. (29 de enero de 2018). Defensa .com. Obtenido de http://www.defensa.com/reportajes/reorganizacion-ejercito-irlandes-impacto-demas- fuerzas-defensa

Departament Of Defence. (s.f.). Recuperado el 18 de enero de 2018, de Roles, Responsibilities and Function: http://www.defence.ie/WebSite.nsf/foi_rolesresp

Department of Defence and Defence Forces. (2015). Annual Report. Newbridge.: copyright.

Obtenido de Anual Report.

Department of Defense. (Agosto de 2015). White Paper on Defense. Recuperado el 25 de enero de 2018, de http://www.defence.ie/WebSite.nsf/WP2015E

Department of Defense. (Octubre de 2017). Statement by the Minister with responsibility for Defence. Recuperado el 28 de enero de 2018, de http://www.defence.ie/WebSite.nsf/ Document+ID/1228874A53106085802581B50053EC A5?openDocument

Department of the Taoiseach. (2018). Strategy Statement 2017-2020. Taoiseach: Roinn an Taoisigh.

Devine, K. (2009). Irish Neutrality and the Lisbon Treaty. Neutrality: Irish Experience, European Experience (p. 1-12). Dublin: Irish School of Ecumenics, Trinity College. 
Dominguez, S. (2007). El objetivo de estudio en la investigación, diversidad aproximaciones. Revista de Educación y Desarrollo, (p. 41-50).

eISB. (1954). Defence Act. Recuperado el 18 de febrero de 2018, de http://www.irishstatutebook.ie/ eli/1954/act/18/section/18/enacted/en/index.html

elmundo.es. (26 de septiembre de 2005). Recuperado el 2 de mayo de 2018, de Fechas Claves en la Historia del IRA: http://www.elmundo.es/elmundo/2005/07/28/internacional/1122552767.html

Encyclopedia Britannica. (2018). Encyclopedia Britannica. Recuperado el 13 de abril de 2018, de Histroy of Ireland: https://www.britannica.com/topic/history-of-Ireland

Escudé, C. (2012). Principios de Realismo Periférico. Buenos Aires Argentina: Lumiere. SA.

Fernandez-Osorio, A. (2017). The Participation of Colombia in United Nations' Multidimensional Peace Operations. Journal of International Peacekeeping, 21(1-2), 83 - 124. https://doi. org/10.1163/18754112-02101003

Fernandez-Osorio, A., \& Latorre-Rojas, J. (2018). (Ed.). La construcción del rol de la mujer militar. Bogotá D.C.: Sello Editorial ESMIC.

Font, T., \& Ortega, P. (2010). Seguridad nacional, seguridad multidimensional, seguridad humana. Papeles de relaciones ecosociales y cambio global, (p. 161-163).

Gómez Sierra, F. (Ed.). (2016). Constitución Politica de Colombia (Vigésimo Novena ed.). Bogotá D.C: Editorial Leyer.

Government Ireland. (2015). Constitution of Ireland. Dublin: Government Publications. Gutiérrez Espada, C. (2006). La Política Común de Seguridad y Defensa (PCSD) de la Unión Europea en el contexto del Derecho Internacional sobre el uso de la Fuerza Armada. En E. López-Jacoiste Díaz, La Politica de Seguridad y Defensa en Europa (p. 15-63). Navarra: Ediciones Universidad de Navarra.

Infante Caffi, M. T. (1986). Regímenes jurídicos de neutralidad. Revista Chilena de Derecho, (p. 157-176).

Instituto Español de Estudios Estratégicos. (6 de febrero de 2005). Cuaderno de Estrategia. CE- 129. Obtenido de La seguridad y la defensa de la Unión Europea: retos y oportunidades.: http://www. ieee.es/Galerias/fichero/cuadernos/CE-129.pdf

Instituto Español de Estudios Estratégicos. (Marzo de 2017). Panorama Estratégico 2017. Obtenido de Ministerio de Defensa: http://www.ieee.es/Galerias/fichero/panoramas/Panorama_ Estrategico_2017.pdf

López, J. I. (1993). Una visión de futuro. Revista Universidad Eafit, (p. 73-80).

López-Jacoiste Díaz, E. (2006). Desafíos de Seguridad para Europa. En E. López-Jacoiste Díaz, La Politica de Seguridad y Defensa en Europa (p. 161- 199). Navarra: Ediciones Universidad de Navarra.

Los recuerdos de McGreevy. (s.f.). Obtenido de Independencia de Irlanda: https://recuerdosmcgreevy. wordpress.com/independencia-de-irlanda/

Maffeo, A. J. (2006). Irlanda y la Primera Guerra Mundial. Revista Relaciones Internacionales, (p. 1-9).

Ministerio de Defensa Nacional. (2015). Política de Defensa y Seguridad. Todos por un Nuevo País. Bogotá D.C., Colombia.

Ministerio de Hacienda. (s.f.). www.minhacienda.gov.co. Recuperado en junio de 2018, de Presupuesto General de la Nación 2018. Ajuste Exitoso, Repunte en Marcha: http://www. 
minhacienda.gov.co/HomeMinhacienda/ShowProperty?nodeId=\%2FOCS\%2F P_MHCP_ WCC-087867\%2F\%2FidcPrimaryFile\&revision=latestreleased

Ministerio de Relaciones Exteriores. (3 de enero de 2018). Obtenido de Ficha de Irlanda: http://www. exteriores.gob.es/Documents/FichasPais/IRLANDA_FICHA\%20PAIS.pdf

Monroy, M. (Noviembre de 2015). La transición de Irlanda del Norte del conflicto al posconflicto: guía para otras latitudes. Recuperado el 3 de enero de 2018, de la Universidad de Guadalajara: http:// www.internaciones.cucsh.udg.mx/index.php/inter/article/view/6889

Neal G., J. (January de 2006). Choosing to Go It Alone: Irish Neutrality in Theorical and Comparative Perspective. International Political Science Review, 27(1), (p. 7-28).

North Atlantic Treaty Organization. (19 de mayo de 2018). Relations with Colombia. Obtenido de https://www.nato.int/cps/en/natohq/topics_143936.htm

Novak, F. (1995). La neutralidad en el derecho internacional contemporáneo. Agenda Internacional, (p. 97-119).

Novakovic, I. S. (2013). Neutrality in the 21st Century - Lessons for Serbia. Stockholm: Colorgrafx.

O’Beirne Ranelagh, J. (2014). Historia de Irlanda. Akal.

OCDE. (s.f.). Des Politiques Meilleures Pour Une Vie Meilleure. Obtenido de http://www.oecd.org/fr/ irlande/lirlandeetlocde.htm

Oficina de información diplomática. (28 de enero de 2018). Ministerio de RREE y Cooperación.

Obtenido de http://www.exteriores.gob.es/Documents/FichasPais/IRLANDA_FICHA\%20PAIS.pdf

Óglaigh na Héireann. (s.f.). Defence Forces Ireland. Recuperado el 17 de febrero de 2018, de Naval Service Organisation: http://www.military.ie/naval-service/organisation/

Ógloigh na Héireann (2018). Defence Forces Ireland. Recuperado el 17 de enero de 2018, de Organisation: http://www.military.ie/army/organisation/

Ojanen, H. (2003). Neutrality and non-alignment in Europe today. Helsinki: Otamedia.

Quintana T., J. R. (2001). Libros Blancos de Defensa. Concertación politica y diseño estratégico comparado. La Paz, Bolivia: Ediciones Ministerio de Defensa de Bolivia.

Redacción Jurídica e Internacional. (15 de agosto de 2001). El Tiempo. Recuperado el 8 de mayo de 2018, de ¿Qué hace el IRA en Colombia?: http://www.eltiempo.com/archivo/documento/ MAM-462860

Retamozo, M. (2010). Constructivismos: Epistemología y Metodología en las Ciencias Sociales.

Revista de Epistemología de las ciencias sociales. Universidad de Chile, 1-31.

Richard Muñoz, M. P., \& González Chávez, J. (2011). Reino Unido de Gran Bretaña e Irlanda del Norte. México: Centro de Documentación, Información y Análisis.

Rizzo, J. M. (2012). ¿¿Irlanda del Norte o el norte de Irlanda? Grupo de Estudios Internacionales Contemporáneos, (p. 1-23).

Rodríguez Fernández, Aitor Javier. (Junio de 2015). El Conflicto en Irlanda del Norte: Sociedad y Cultura. Antecedentes del Conflicto. España: Universidad de Almería.

Russell, R., \& Tokatlian, J. (2013). Neutralidad y política mundial, una mirada desde las relaciones internacionales. Revista Estudios, (p. 24-39).

Serrano Álvarez, J. M. (2018). El paradigma de la guerra en el siglo XX. Revista Científica General José María Córdova, 16(23), 23-42. https://doi.org/10.21830/19006586.305

Storey, W. (2007). US Government and Politics. George Square: GraphyCems. 
The World Bank. (s.f.). DataBank. World Development Indicators. Recuperado el 4 de septiembre de 2018, de Fuerzas Armadas de Colombia. Total de personal.: http://databank.worldbank.org/ data/source/2/Type/metadata?series=MS.MIL.TOTL.P1\&s avedlg=1,1\&l=es,es

Torrijos Rivera, V., \& Abella Osorio, J. (2018). El comportamiento de las FARC tras la firma de los acuerdos de La Habana. Revista Científica General José María Córdova, 16(24), 31-60. https:// doi.org/10.21830/19006586.342

Universidad Complutense de Madrid. (2010). «El pivote geográfico de la historia», el seguimiento de la geopolítica clásica y la persistencia de una interpretación telúrica de la política global. Revista de estudios sobre espacio y poder, (p. 321-331).

Villadangos, E. S. (2012). Irlanda: Reforma Constitucional versus Convención Constitucional. Teoría y Realidad Constitucional, (p. 411-432).

Zambrano, F. (1993). Región, Nación e Identidad. En F. Z. González, Violencia en la región andina: El caso Colombia (p. 1-17). Bogotá D.C.: CINEP. 